\title{
Correspondence
}

\section{Switch it off on eclipse day}

The total solar eclipse in the United States on 21 August will allow millions of people to participate in planetary science (see Nature 545, 386; 2017). They can reflect, too, on solar energy, energy conservation and the reliability of electrical systems based on alternative energy.

Commercial solar-power production during the partial eclipse in California, for example, will drop from around 9 to 3 gigawatts between 9:00 and 10:30 local time, rising back to about $9 \mathrm{GW}$ by noon. The California Independent System Operator is procuring extra resources to compensate.

Alternatively, those enjoying the eclipse could simply cut their electricity usage for the duration. The president of the California Public Utilities Commission, Michael Picker, suggests that such a community effort would send a message to the US Department of Energy in response to Secretary Rick Perry's request for a review of the possible negative effects of alternative energy on the electrical distribution system.

Steve Elgar Woods Hole

Oceanographic Institution, Massachusetts, USA.

elgar@whoi.edu

\section{Philanthropic risks can hit home runs}

As an adviser to medicalresearch foundations on effective donation (see C. Fiennes Nature 546, 187; 2017), I contend that philanthropic capital has an intrinsic advantage over public funding: it thrives on risk. This encourages the testing of bold ideas, even when there's a high chance they might not work out.

Philanthropic capital can withstand failed research outcomes more readily than can public or commercial capital because it is not subject to government processes or shareholders' expectations. It can be swiftly channelled into cuttingedge research that is high risk and high reward. Although the conventional success rate may be lower, the fruitful hits are home runs. And even when fundees fail to fulfil their objectives, a clear answer can count as a hit in itself.

Ideas that test positive open the door to government and commercial capital. In the mid1990s, for instance, Mike Milken gave a small, unrestricted grant through the Prostate Cancer Foundation to James Allison to explore the promising, yet under-appreciated, field of cancer immunotherapy. Allison went on to win government and commercial funding to realize that promise and bring lifesaving treatments to market.

As well as the "science of philanthropy" that Fiennes calls for, we need to ask how philanthropic funding can catalyse change beyond that achievable through conventional funding sources.

Melissa L. Stevens Milken Institute Center for Strategic Philanthropy, Washington DC, USA.

mstevens@milkeninstitute.org

\section{Manage chemicals and waste globally}

The conferences of the parties to the Basel, Rotterdam and Stockholm Conventions in spring 2017 called for better global management of chemicals and waste to meet the United Nations Sustainable Development Goals (particularly $3,6,12$ and 14 ; see go.nature. com/2kw1xsy). As delegates from the Chinese government and the Basel Convention Regional Centre for Asia and the Pacific, we are concerned about the loss of political will among developed nations to provide the technical assistance to back such plans in developing countries.

A reason for this reluctance might be that funding for tackling global environmental issues is already stretched. Another US $\$ 4.37$ billion will be needed to implement the Stockholm Convention in 2018-22, and the global economic downturn has shrunk the Basel Convention Trust Fund, which covers such technical assistance.

Fortunately, some companies and non-governmental organizations (NGOs) are cooperating to improve the management of industrial chemicals and waste. For example, the urban mining company GEM based in Shenzhen, China, has instigated recycling schemes. And NGOs such as IPEN (www.ipen.org) are publicizing the Stockholm Convention's moratorium on the recycling of persistent organic pollutants.

Quanyin Tan, Jinhui Li

Tsinghua University, Beijing,

China.

jinhui@tsinghua.edu.cn

\section{Taxonomy: refine rather than stabilize}

Conservation policies should be embracing the insights into evolutionary history revealed by the refinement of taxonomic knowledge. Stephen Garnett and Les Christidis instead view these refinements as "taxonomy anarchy" that destabilizes species lists (Nature 546, 25-27; 2017).

They argue that taxonomic inflation can artificially increase the count of species under threat, citing a doubling in the number of recognized ungulate species. But, as well as updating classifications scarcely changed since the nineteenth century (see C. G. Groves and P. R. Grubb Ungulate Taxonomy; Johns Hopkins Univ. Press, 2011), that doubling of diversity highlights the high conservation priority both of the spiral-horned antelopes in African biodiversity hotspots and the evolutionarily distinct lineages of goats and sheep in
Northern Hemisphere mountain ranges.

In mapping the evolutionary history of what it classifies, a taxonomy is much more than a species list. We see aspirations to stabilize taxonomy as a cul-de-sac that further isolates conservation policy from science. A proactive strategy should incorporate this new knowledge to mitigate the impacts of unprecedented global change on ecosystems and their dependent species.

Fenton P. D. Cotterill University of Stellenbosch, South Africa. Colin P. Groves Australian National University, Canberra, Australia.

Peter J. Taylor University of

Venda, Thohoyandou,

South Africa.

fcotterill@gmail.com

\section{CRISPR book review - Doudna responds}

Nathaniel Comfort suggests that the purpose of our book

A Crack in Creation is to show that I am "the true hero of CRISPR" (Nature 546, 30-31; 2017). On the contrary, the book offers my personal reflections as CRISPRCas gene editing took off, viewed from the perspective of my research team at the University of California, Berkeley.

My aim in writing this book with my former student Sam Sternberg was to demonstrate the importance of basic research and the value of collaboration in developing this groundbreaking technology. It describes the crucial scientific contributions and insights of our collaborators Emmanuelle Charpentier and her student Krzysztof Chylinski, for example.

The success of our approach has now been abundantly confirmed by the rapid application of CRISPR-Cas gene editing in virtually all types of cells and settings.

Jennifer Doudna University of California, Berkeley, USA. jadoudna@gmail.com 